\title{
Combined treatment with simvastatin and rapamycin attenuates cardiac allograft rejection through the regulation of $T$ helper 17 and regulatory $T$ cells
}

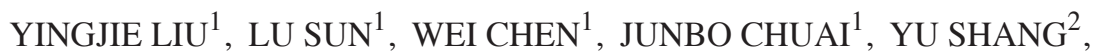 \\ DONGYANG ZHANG ${ }^{1}$, BICHENG FU ${ }^{1}$, HAI TIAN ${ }^{1}$ and SHULIN JIANG ${ }^{1}$
}

${ }^{1}$ Department of Cardiovascular Surgery, The Second Affiliated Hospital of Harbin Medical University, Harbin, Heilongjiang 150086; ${ }^{2}$ Department of Respiratory Medicine, Harbin First Hospital, Harbin, Heilongjiang 150010, P.R. China

Received December 13, 2016; Accepted July 7, 2017

DOI: $10.3892 / \mathrm{etm} .2017 .5635$

\begin{abstract}
Allograft rejection is an important issue post cardiac transplantation. In order to investigate the effect of combined treatment with simvastatin and rapamycin on allograft rejection, a cardiac transplantation rat model was employed in the present study. The survival time of rats following cardiac transplantation was recorded, while histopathological alterations were assessed by hematoxylin and eosin staining. The levels of transcription factors were measured by reverse transcription-quantitative polymerase chain reaction. In addition, the levels of $\mathrm{CD}^{+}{ }^{+}$interleukin (IL)- $17^{+}$cells and $\mathrm{CD} 4^{+}$forkhead box $\mathrm{P} 3(\mathrm{FOXP} 3)^{+}$cells in the allografts and $\mathrm{CD} 4^{+} \mathrm{T}$ cells and $\mathrm{CD} 8^{+} \mathrm{T}$ cells in the spleens were detected by flow cytometry. The results of the current study demonstrated that, following treatment with simvastatin and rapamycin, the survival time of model rats was prolonged, and the histopathological damage was attenuated. Treatment with simvastatin and rapamycin also led to decreased retinoic acid receptor-related orphan receptor $\gamma \mathrm{t}(\mathrm{ROR} \gamma \mathrm{t})$ level, increased FOXP3 level, reduced levels of $\mathrm{CD} 4^{+} \mathrm{IL}-17^{+}, \mathrm{CD} 4^{+} \mathrm{T}$ and $\mathrm{CD} 8^{+} \mathrm{T}$ cells, and increased level of $\mathrm{CD}^{+}{ }^{+} \mathrm{FOXP} 3^{+}$cells. In conclusion, the current study observed that simvastatin and rapamycin performed a synergistic effect to reduce cardiac transplantation rejection. Thus, combined therapy of simvastatin and rapamycin may be a promising adjuvant therapy to reduce rejection post cardiac transplantation.
\end{abstract}

Correspondence to: Dr Shulin Jiang or Dr Hai Tian, Department of Cardiovascular Surgery, The Second Affiliated Hospital of Harbin Medical University, 246 Xuefu Road, Harbin, Heilongjiang 150086, P.R. China

E-mail: sljiang36@163.com

E-mail: tian_hai06@sina.com

Key words: allograft rejection, cardiac transplantation, rapamycin, simvastatin, T helper 17 cell, regulatory $\mathrm{T}$ cell

\section{Introduction}

Cardiac transplantation is a primary treatment for patients with end-stage heart failure (1). Despite of the progress of surgical techniques, allograft rejection is a major cause of mortality post cardiac transplantation. Immune responses serve important roles in transplantation rejection and immunosuppressive agents are usually employed to prevent allograft rejection.

Statins exhibit immunomodulatory effects and are beneficial following transplantation due to reducing the transplant rejection and allograft vasculopathy rates (2-5). Simvastatin is a type of cholesterol-lowering agent that also serves an immunomodulatory role through the inhibition of superantigen-mediated $\mathrm{T}$ cell activation (2). It is widely used for the reduction of cardiovascular morbidity and mortality $(6,7)$, and pretreatment with simvastatin has been reported to decrease the apoptosis and necroptosis in cardiac allograft ischemia/reperfusion (8).

The agent rapamycin is an inhibitor of the mammalian target of rapamycin protein and an autophagy stimulator. It blocks signal transduction through different cytokine receptors, arresting the cell cycle of $\mathrm{T}$ cells and thus exerting an immunosuppressive effect (9-11). Rapamycin is also able to suppress fibrosis subsequent to liver transplantation, as well as chronic graft vascular disease following cardiac transplantation $(12,13)$.

Simvastatin and rapamycin demonstrate immunomodulatory effects; however, the effect of combined treatment with these two agents on cardiac allograft rejection remains unclear. In the present study, the effect of combined treatment with simvastatin and rapamycin on cardiac allograft rejection was investigated in a rat model of cardiac transplantation. The study suggests that combined treatment with simvastatin and rapamycin may be a promising adjuvant therapy to prevent allograft rejection post cardiac transplantation.

\section{Materials and methods}

Materials. A total of 72 3-month-old male Sprague Dawley and Wistar rats (200-250 g) were obtained from the Experiment Animal Center of the Second Affiliated Hospital of Harbin 
Medical University (Harbin, China). The rats were housed under standard conditions (temperature $22 \pm 4^{\circ} \mathrm{C}$, humidity $55 \pm 15 \%, 16 / 8 \mathrm{~h}$ light/dark cycle) with access to food and water ad libitum. The care and use of animals was in accordance with the Guide for the Care and Use of Laboratory Animals (14) and was approved by the Experimental Animal Ethics Committee of the Second Affiliated Hospital of Harbin Medical University.

Cardiac transplantation procedure. Wistar rats were used as the donors and Sprague Dawley rats were used as the recipients. Donor and recipient rats were food-fasted for $12 \mathrm{~h}$ and water-fasted for $4 \mathrm{~h}$ before cardiac transplantation surgery, and then rats were subjected to surgery. Briefly, the donor rat was anesthetized with chloral hydrate (Sigma-Aldrich; Merck KGaA, Darmstadt, Germany; 400 mg/kg, intraperitoneal injection) and a midline abdominal incision was made. Ice-cold cardioplegic solution with heparin $(200 \mathrm{U} / \mathrm{ml})$ was injected into the inferior vena cava. Next, the abdominal aorta and inferior vena cava were transected and blood was removed. The pericardium was opened and cardioplegic solution (normal saline $470 \mathrm{ml}, 10 \%$ potassium chloride $7.5 \mathrm{ml}, 25 \%$ magnesium sulfate $2 \mathrm{ml}, 5 \%$ calcium chloride $1.5 \mathrm{ml}, 10 \%$ procaine $2 \mathrm{ml}, 5 \%$ sodium carbonate $20 \mathrm{ml}$ ) was injected through the root of the ascending aorta. The heart was washed with ice-cold balanced salt solution several times to ensure full cardiac arrest. Subsequently, the inferior and right superior venae cavae were ligatured and transected, and the auricula dextra was ligatured together with the right superior vena cava. The ascending aorta, pulmonary artery and innominate artery were then detached from the surrounding tissues, followed by transection of the ascending aorta in the proximal innominate artery and transection of the pulmonary artery in the proximal pulmonary artery. The heart was then lifted up, the left and right pulmonary veins and left superior vena cava were ligatured, and the heart was resected and kept in ice-cold balanced salt solution. Prior to cardiac transplantation, the recipient rat was anesthetized with chloral hydrate and a midline abdominal incision was made. The intestinal loop was pushed to the right and protected with warm saline gauze, while the inferior vena cava and the aorta were dissected. The donor heart was protected with ice-cold saline cotton slices and transplanted into the abdomen of the recipient through anastomosis. The left side of the aortic anastomosis was initially completed, and the heart was then turned over to the left side for completion of the right side of aortic anastomosis. Subsequently, the pulmonary artery was anastomosed to the inferior vena cava in a similar pattern without turning over the heart. After the anastomosis was completed, the clamp was removed and the abdomen was closed. Rats received 5,000 U gentamycin (Harbin Pharmaceutical Group Co., Ltd., Harbin, China; intraperitoneal injection) to prevent infection. Following cardiac transplantation, the rats were kept in an incubator and fed with warm glucose solution after awaking. The viability of the allograft was assessed every day by palpation. Cardiac transplantation with a strongly beating allograft that lasted for $>72 \mathrm{~h}$ was regarded as successful.

Simvastatin and rapamycin treatment. The rats were divided into four groups, including the untreated, simvastatin, rapamycin and rapamycin+simvastatin groups, with 18 rats in each. Rats in the untreated group received only cardiac transplantation surgery without further treatment. Rats in the rapamycin group received cardiac transplantation and rapamycin (1 mg/kg/day; intraperitoneal injection) at 0-7 days post-surgery. Rats in the simvastatin group received cardiac transplantation and simvastatin treatment $(20 \mathrm{mg} / \mathrm{kg} / \mathrm{day}$; intragastric administration) at 1-7 days prior to surgery. Rats in the rapamycin+simvastatin group received cardiac transplantation, simvastatin pretreatment $(20 \mathrm{mg} / \mathrm{kg} / \mathrm{day}$ at $1-7$ days before surgery; intragastric administration) and rapamycin treatment $(1 \mathrm{mg} / \mathrm{kg} / \mathrm{day}$ at $0-7$ days post-surgery; intraperitoneal injection). In each group, 6 rats were used for survival analysis, while 4 rats were sacrificed respectively on days 3,5 and 7 post-surgery. The allografts and spleens were obtained under sterile conditions. The samples were divided into three sections, which were then subjected to immediate detection by flow cytometry, fixed in $4 \%$ paraformaldehyde for subsequent histopathological examination, or stored in liquid nitrogen for subsequent reverse transcription-quantitative polymerase chain reaction (RT-qPCR).

Histopathology examination. Following fixation with $4 \%$ paraformaldehyde and dehydration in increasing grades of ethanol, the allografts from each group were embedded into paraffin and cut into $5-\mu \mathrm{m}$ sections. The sections were subjected to routine hematoxylin and eosin (H\&E) staining and observed under an optical microscope (Olympus Corp., Tokyo, Japan) at x100 magnification. The parenchymal rejection (PR) score (15) of the stained sections was determined as follows: 0 , no rejection; 1 , focal mononuclear cell infiltration without necrosis; 2 , focal mononuclear cell infiltration with necrosis; 3 , multifocal infiltration with necrosis; and 4, widespread infiltration with hemorrhage and vasculitis.

$R T-q P C R$. Total RNA from the allografts in each group was extracted using TRIzol reagent (Invitrogen; Thermo Fisher Scientific, Inc., Waltham, MA, USA) according to the manufacturer's protocol. Next, the RNA purity was assessed and then the RNA was reverse transcribed into cDNA with a cDNA first-chain reverse transcription kit (HaiGene Bio, Harbin, China). The levels of retinoic acid receptor-related orphan receptor $\gamma \mathrm{t}(\mathrm{ROR} \gamma \mathrm{t})$ and forkhead box P3 (FOXP3) were then measured using qPCR (SYBR Green method) with cDNA as a template and the following primers: ROR $\gamma \mathrm{t}$ forward, 5'-TGCAAGACTCATCGACAAGG-3', and reverse, 5'-AGGGGATTCAACATCAGTGC-3'; FOXP3 forward, 5'-ACTGGGGTCTTCTCCCTCAA-3', and reverse, 5'-GTG GGAAGGTGCAGAGTAG-3'; GAPDH forward, 5'-AAC TCCCATTCTTCCACCTTT-3', and reverse, 5'-CTCTTG CTCTCAGTATCCTTG-3'. The PCR mixture included $2 \mu 1$ cDNA, $4 \mu 1$ 5x Golden HS SYBR Green qPCR Mix (HaiGene Bio), $0.8 \mu 1$ forward primer, $0.8 \mu 1$ reverse primer, and water to give a final volume of $20 \mu$ l. The thermocycling conditions were as follows: $95^{\circ} \mathrm{C}$ for $15 \mathrm{~min}$ followed by 40 cycles of $95^{\circ} \mathrm{C}$ for $10 \mathrm{sec}$ and $60^{\circ} \mathrm{C}$ for $30 \mathrm{sec}$. The mRNA levels of ROR $\gamma t$ and FOXP3 were normalized to GAPDH, and the relative mRNA levels were calculated using the $2^{-\Delta \Delta \mathrm{Cq}}$ method (16). 
Detection of $\mathrm{CD}^{+}$and $C D 8^{+}$T cells in spleens. The spleens of rats in each group were obtained and made into tissue homogenates. Subsequent to passing through a 200-mesh sieve, single-cell suspension was collected and resuspended in $5 \mathrm{ml}$ red blood cell lysis buffer (HaiGene Bio) in order to eliminate red blood cells. Thereafter, cells were washed with phosphate-buffered saline and resuspended in $5 \mathrm{ml}$ fetal bovine serum Staining Buffer (BD Biosciences, Franklin Lakes, NJ, USA; cat. no. 554656). The cells were then incubated with allophycocyanin (APC)-labeled CD45 antibody (eBioscience; Thermo Fisher Scientific, Inc.; 1:100; cat. no. 17-0461) plus fluorescein isothiocyanate (FITC)-labeled CD4 antibody (eBioscience; Thermo Fisher Scientific, Inc.; 1:100; cat. no. 11-0040), or with APC-labeled CD45 antibody plus phycoerythrin (PE)-labeled CD8 antibody (eBioscience; Thermo Fisher Scientific, Inc.; 1:100; cat. no. 12-0084) at $4^{\circ} \mathrm{C}$ for $20 \mathrm{~min}$ in the dark. Subsequently, the cells were analyzed using flow cytometry.

Detection of $\mathrm{CD}^{+} \mathrm{FOXP}^{+}$cells in cardiac allografts. The allografts of rats in each group were harvested, cut into $1 \mathrm{~mm}$ sections and digested with Collagenase D (Sigma-Aldrich; Merck KGaA) for $6 \mathrm{~h}$. Subsequent to passing through a 200-mesh sieve, a single-cell suspension was obtained and treated with red blood cell lysis buffer. The cells were then collected and added into Dulbecco's modified Eagle's medium containing $50 \mathrm{ng} / \mathrm{ml}$ ionomycin (BioAustralis, Smithfield, Australia) and $50 \mathrm{ng} / \mathrm{ml}$ phorbol 12-myristate 13-acetate (PMA; Sigma-Aldrich; Merck KGaA). Following incubation for $3 \mathrm{~h}, 2 \mu \mathrm{g} / \mathrm{ml}$ brefeldin A (Cell Signaling Technology, Inc., Beverly, MA, USA) were added into cells and incubated for an additional $1 \mathrm{~h}$. Thereafter, cells were collected, resuspended in Staining Buffer and incubated with FITC-labeled CD4 antibody (eBioscience; Thermo Fisher Scientific, Inc.; 1:100; cat. no. 11-0040) at $4^{\circ} \mathrm{C}$ for $20 \mathrm{~min}$ in the dark. Following incubation, the cells were collected and resuspended in Human FOXP3 Buffer A (BD Biosciences) and incubated for $10 \mathrm{~min}$. After washing with Staining Buffer, cells were resuspended in Human FOXP3 Buffer C (BD Biosciences) and incubated for 30 min. After washing with Staining Buffer, cells were incubated with PE-labeled FOXP3 antibody (eBioscience; Thermo Fisher Scientific, Inc.; 1:100; cat. no. 12-5773) in the dark for $30 \mathrm{~min}$ at room temperature. Subsequent to washing, the cells were collected, resuspended in Staining Buffer and analyzed with flow cytometry.

Detection of $\mathrm{CD}^{+}$interleukin $(\mathrm{IL})-17^{+}$cells in cardiac allografts. Allografts from each group were harvested, and a signal-cell suspension was obtained as described earlier. Following the removal of red blood cells, cells were treated with ionomycin, PMA and brefeldin A in accordance with the aforementioned experimental steps. Next, cells were collected, resuspended in Staining Buffer and incubated with FITC-labeled CD4 antibody in the dark at room temperature for $20 \mathrm{~min}$. Following incubation, cells were collected and resuspended in Fixation and Permeabilization Solution (BD Biosciences) and incubated in the dark at room temperature for $10 \mathrm{~min}$. Cells were then washed with Perm/Wash Buffer (BD Biosciences) and incubated with PE-labeled IL-17 antibody (eBioscience; Thermo Fisher Scientific, Inc.; 1:100;
Table I. Survival time of rats following cardiac transplantation.

\begin{tabular}{lcc}
\hline Groups & No. rats & Survival time (days) \\
\hline Untreated & 6 & $7.5 \pm 0.95$ \\
Simvastatin & 6 & $11.66 \pm 1.51^{\mathrm{a}}$ \\
Rapamycin & 6 & $20.17 \pm 1.94^{\mathrm{b}}$ \\
Rapamycin+simvastatin & 6 & $30.67 \pm 2.50^{\mathrm{b}-\mathrm{d}}$
\end{tabular}

${ }^{\mathrm{a}} \mathrm{P}<0.01$ and ${ }^{\mathrm{b}} \mathrm{P}<0.001$ vs. untreated group. ${ }^{\mathrm{c}} \mathrm{P}<0.001$ vs. simvastatin group. ${ }^{\mathrm{d}} \mathrm{P}<0.001$ vs. the rapamycin group.

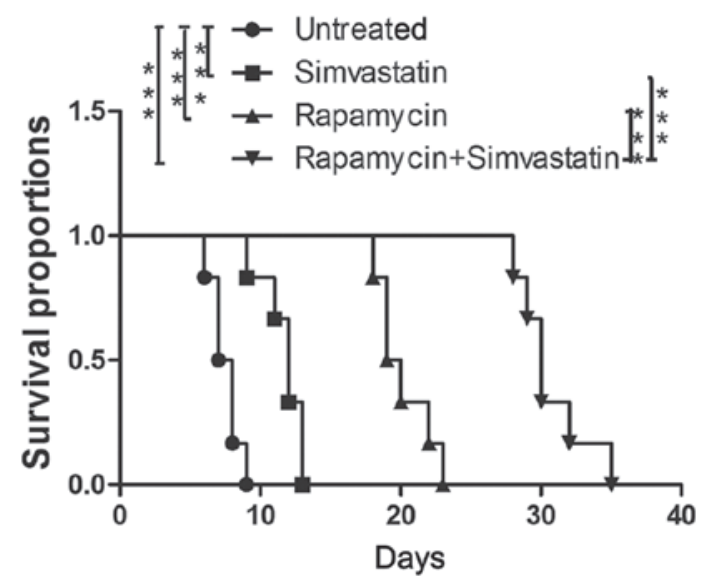

Figure 1. Survival of the cardiac allografts in the rats was assessed every day by palpation, and the survival time was recorded $(n=6) .{ }^{* * *} \mathrm{P}<0.001$.

cat. no. 12-7177) in the dark for $30 \mathrm{~min}$. Finally, the cells were washed with Perm/Wash Buffer and analyzed with flow cytometry.

Statistical analysis. Experimental results are presented as the mean \pm standard deviation. Kaplan-Meier survival curves were drawn according to the survival time of rats post-surgery. Differences in the PR scores were analyzed using Mann-Whitney U test. Difference between groups was analyzed with one-way analysis of variance. $\mathrm{P}<0.05$ was considered to indicate differences that were statistically significant.

\section{Results}

Combined treatment with simvastatin and rapamycin prolongs the survival time of rats. Subsequent to cardiac transplantation and treatment with simvastatin and/or rapamycin, the survival time of rats was recorded (Table I). In rats receiving simvastatin or rapamycin, the survival times were prolonged compared with those in the untreated group. In rats receiving combined treatment with simvastatin and rapamycin (simvastatin+rapamycin group), the survival time was significantly prolonged compared with those in the simvastatin or rapamycin group (Fig. 1; P<0.001). These results demonstrated that combined treatment with simvastatin and rapamycin showed a beneficial effect against the cardiac allograft rejection. 
A

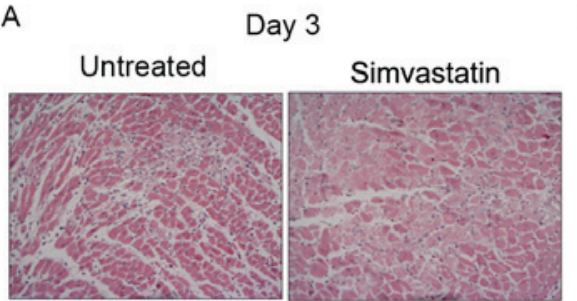

Rapamycin

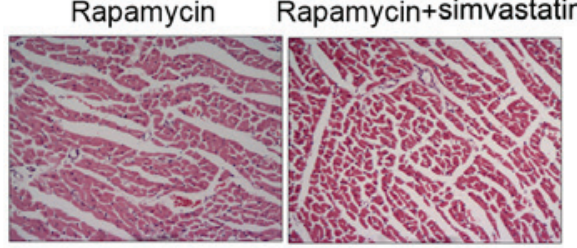

D

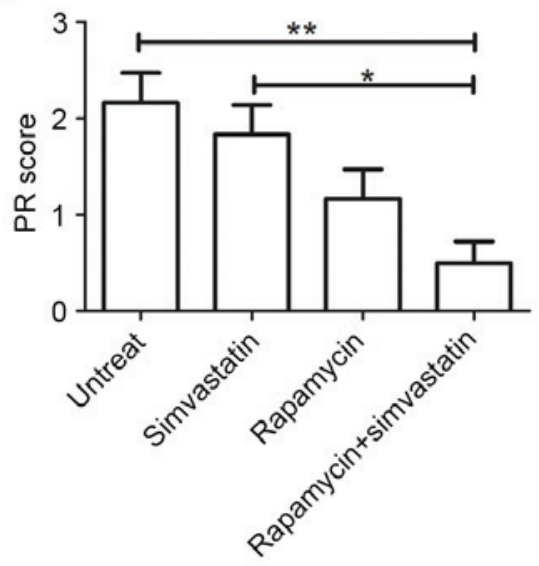

B

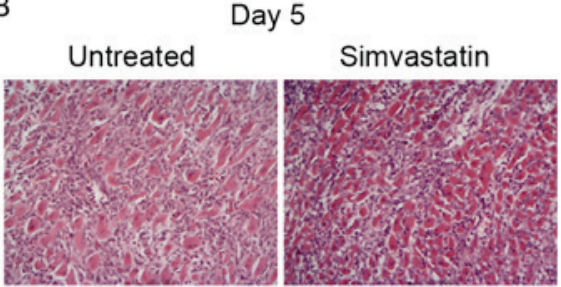

Rapamycin Rapamycin+simvastatin

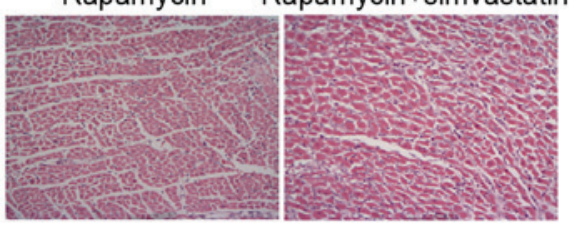

$E$

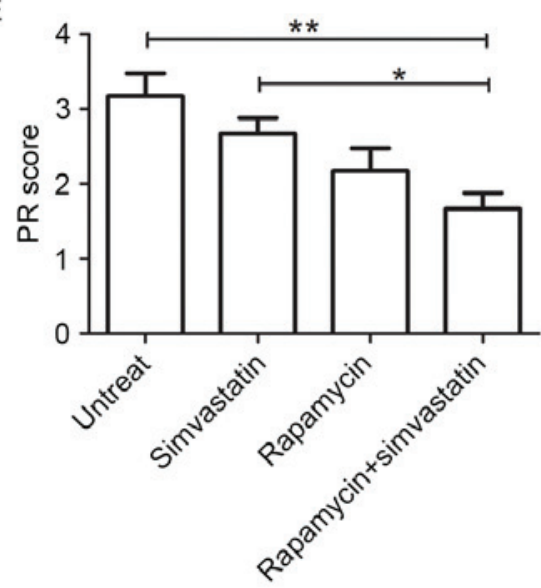

C

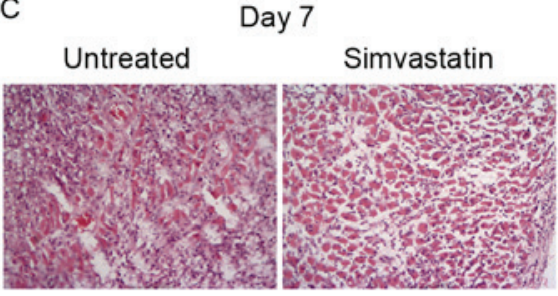

Rapamycin Rapamycin+simvastatin

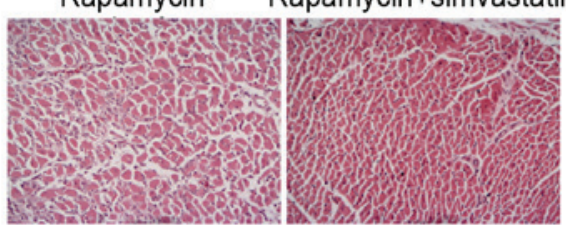

$\mathrm{F}$

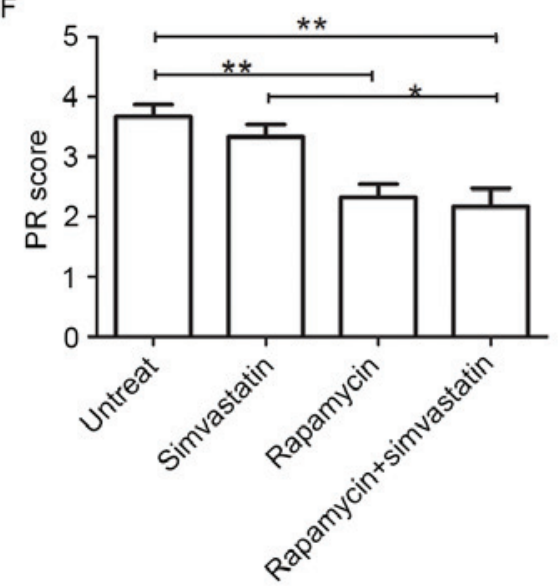

Figure 2. Combined treatment with simvastatin and rapamycin attenuated the pathological damage. Recipient rats were sacrificed and the histopathological damage in each group was assessed by hematoxylin and eosin staining on (A) day 3, (B) day 5 and (C) day 7 after cardiac transplantation (magnification, x100). The PR scores in each group were also assessed on (D) day 3, (E) day 5 and (F) day $7(n=4)$. ${ }^{*} \mathrm{P}<0.05$ and ${ }^{* * *} \mathrm{P}<0.01$. PR $<$ parenchymal rejection.

Combined treatment with simvastatin and rapamycin attenuates histopathological damage. Subsequent to cardiac transplantation and treatment with simvastatin and/or rapamycin, H\&E staining was performed to detect the histopathological changes in the allografts. As shown in Fig. 2, allografts in the untreated group presented a large amount of inflammatory cell infiltration, interstitial hemorrhage and necrocytosis. However, following treatment with simvastatin or rapamycin alone, the allografts demonstrated a smaller amount of inflammatory cell infiltration and swelling. Following combined treatment with simvastatin and rapamycin, the histopathological damage was attenuated on days 3, 5 and 7 with declined PR scores observed (Fig. 2). These results demonstrated that combined treatment with simvastatin and rapamycin attenuated the histopathological damage in the allografts.

Combined treatment with simvastatin and rapamycin diminishes $C D 4^{+}$and $C D 8^{+} T$ cells in the spleens. To further examine the mechanism underlying the protective effect of combined treatment with simvastatin and rapamycin against allograft rejection, the levels of $\mathrm{CD}^{+}$and $\mathrm{CD}^{+} \mathrm{T}$ cells in the spleens in each group were detected by flow cytometry. The results of flow cytometry revealed that treatment with simvastatin reduced the level of $\mathrm{CD}^{+} \mathrm{T}$ cells on days 3 and 7 compared with the untreated group; treatment with rapamycin also decreased the level of $\mathrm{CD}^{+} \mathrm{T}$ cells on days 3,5 and 7 (Fig. 3). Following combined treatment with simvastatin and rapamycin, the levels of $\mathrm{CD}^{+} \mathrm{T}$ cells were decreased compared with the untreated group and were also lower than compared with the simvastatin or rapamycin groups (Fig. 3). In addition, the levels of $\mathrm{CD}^{+} \mathrm{T}$ cells presented a decrease following simvastatin or rapamycin treatment, and a lower level of $\mathrm{CD}^{+} \mathrm{T}$ cells was observed following treatment with simvastatin+rapamycin (Fig. 4). These results demonstrated that combined treatment with simvastatin and rapamycin decreased the levels of $\mathrm{CD}^{+}$and $\mathrm{CD}^{+} \mathrm{T}$ cells in the spleens, and that the protective effect of this treatment may be associated with the immune system.

Combined treatment with simvastatin and rapamycin decreases Thelper 17 (Th17) cells in the cardiac allografts. The levels of Th17 cells in the allografts were detected by flow cytometry. Compared with the untreated group, the levels of Th17 cells in the allografts were decreased subsequent to treatment with simvastatin or rapamycin. Compared with the simvastatin or rapamycin group, the simvastatin+rapamycin group had a lower level of Th17 cells (Fig. 5A-F). These results demonstrated that the combined treatment decreased the levels of Th17 cells in the allografts. ROR $\gamma t$ is essential for 

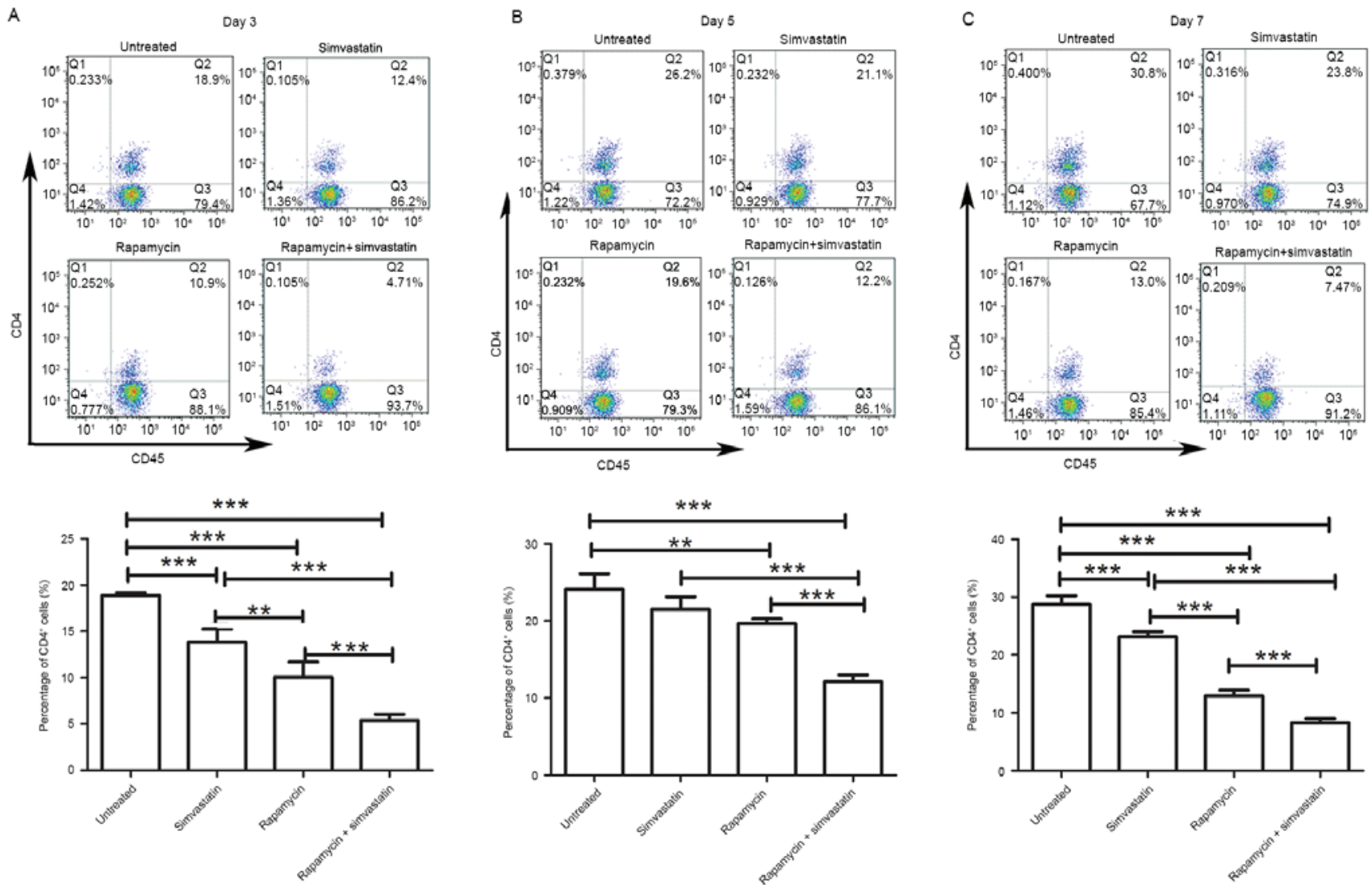

Figure 3. Combined treatment with simvastatin and rapamycin decreased the levels of CD4 ${ }^{+} \mathrm{T}$ cells in the spleens of rats. Flow cytometry was used to analyze the levels of $\mathrm{CD}^{+} \mathrm{T}$ cells in the spleens on (A) day 3 , (B) day 5 and (C) day 7 post cardiac transplantation $(\mathrm{n}=4)$. ${ }^{* * *} \mathrm{P}<0.01$ and ${ }^{* * *} \mathrm{P}<0.001$.
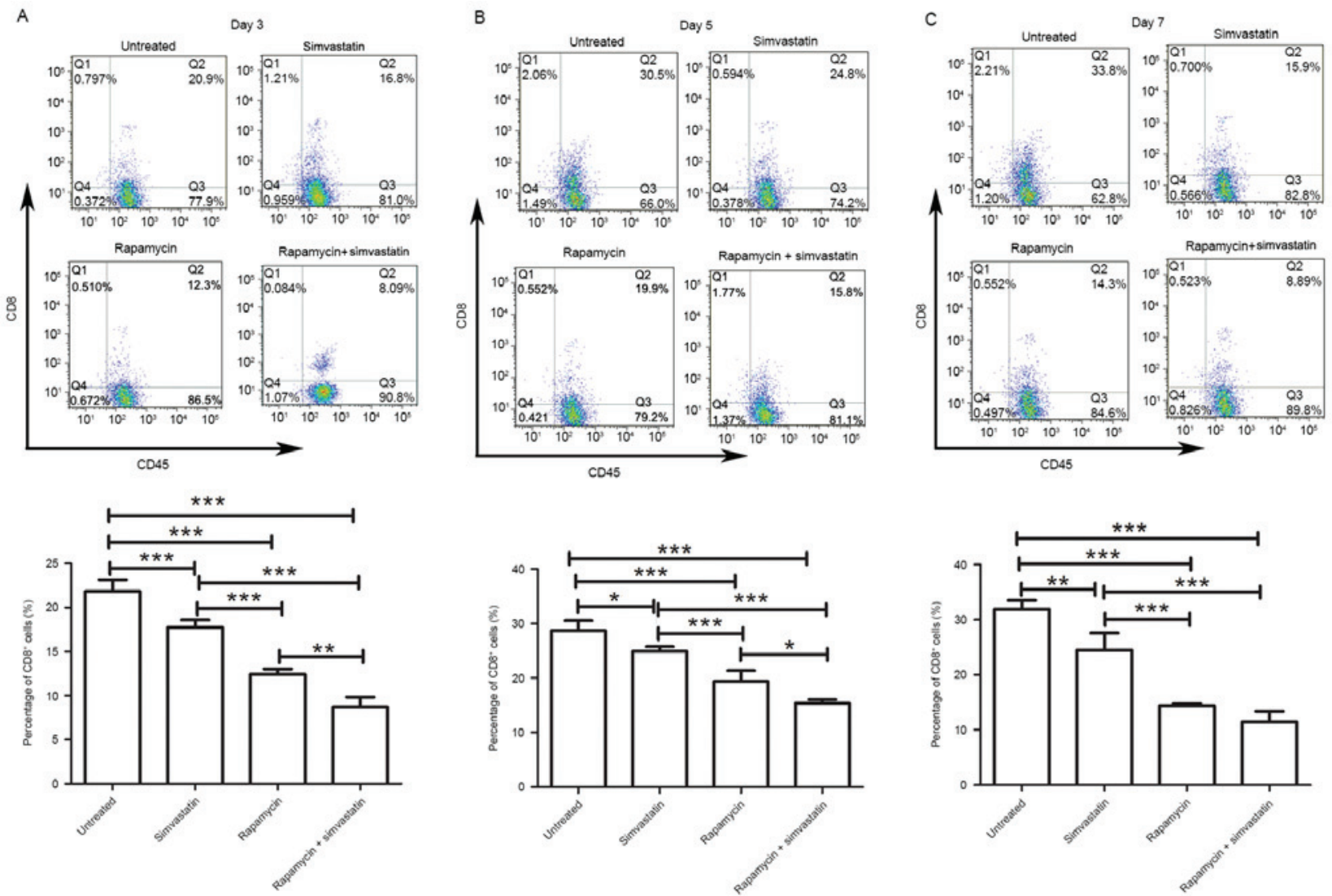

Figure 4. Combined treatment with simvastatin and rapamycin decreased the levels of CD8 ${ }^{+} \mathrm{T}$ cells in spleens. Flow cytometry was used to analyze the levels of $\mathrm{CD}^{+} \mathrm{T}$ cells in the spleens on (A) day $3,(\mathrm{~B})$ day 5 and $(\mathrm{C})$ day 7 post cardiac transplantation $(\mathrm{n}=4)$. ${ }^{*} \mathrm{P}<0.05,{ }^{* * *} \mathrm{P}<0.01$ and ${ }^{* * *} \mathrm{P}<0.001$. 
A

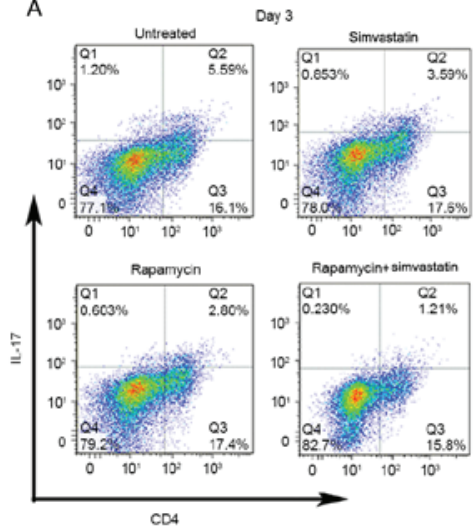

D

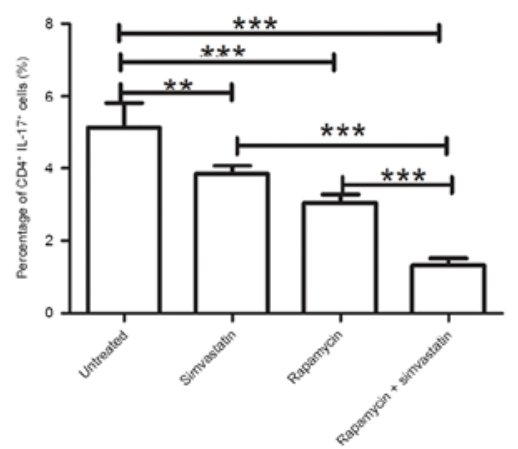

G

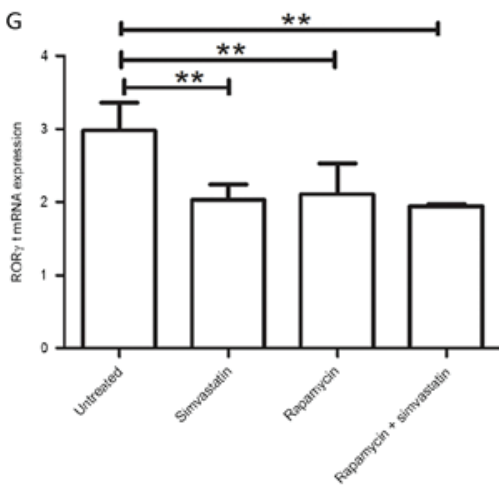

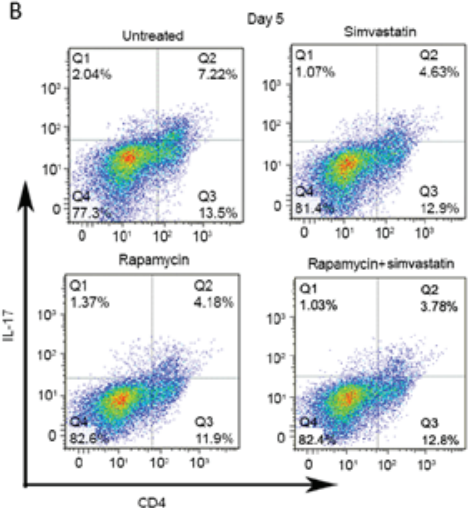

$\mathrm{E}$
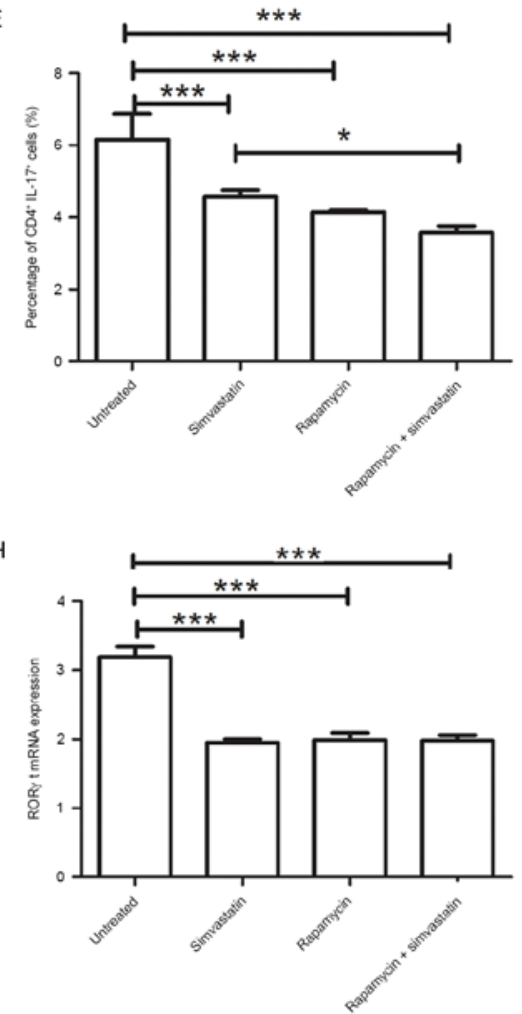
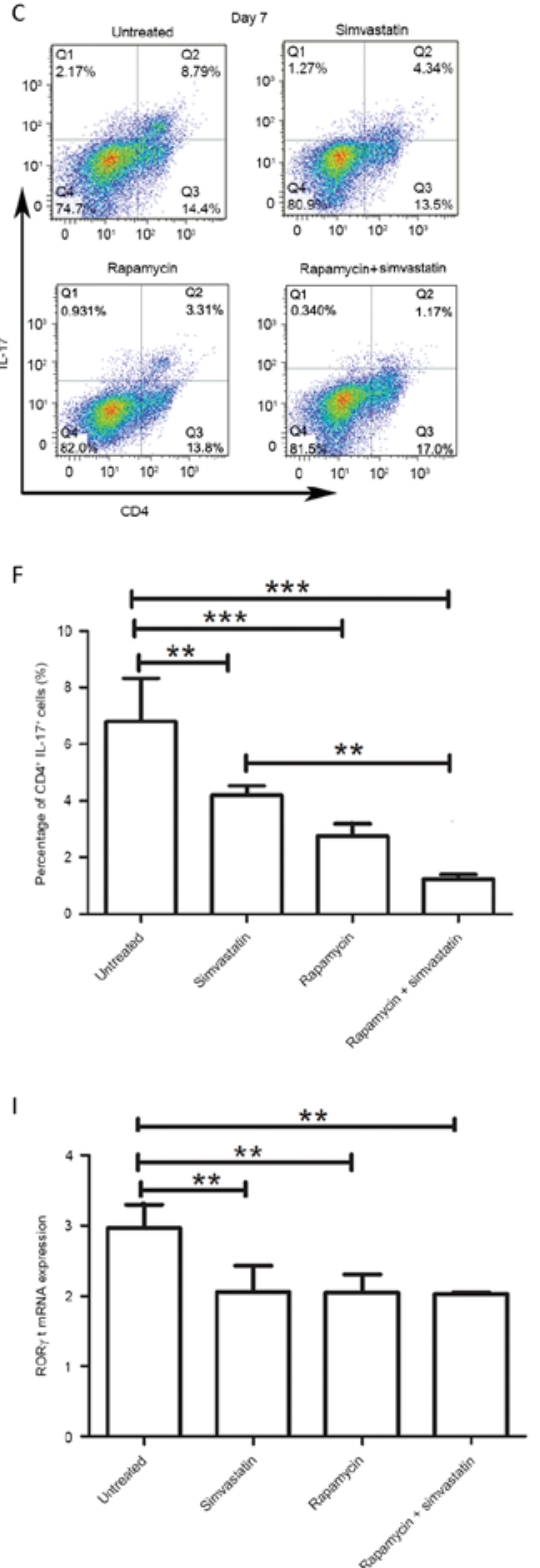

Figure 5. Combined treatment with simvastatin and rapamycin decreased the levels of Th17 cells in allografts. Flow cytometry was used to analyze the levels of Th17 cells in the allografts of each group on (A) day 3,(B) day 5 and (C) day 7 post cardiac transplantation. The percentages of Th17 cells in the allografts on (D) day 3, (E) day 5 and (F) day 7 are shown, as measured by flow cytometry. Following cardiac transplantation and treatment with simvastatin and rapamycin, the mRNA levels of ROR $\gamma \mathrm{t}$ in the allografts of each group were detected by reverse transcription-quantitative polymerase chain reaction on $(\mathrm{G})$ day 3, (H) day 5 and (I) day $7(\mathrm{n}=4) .{ }^{*} \mathrm{P}<0.05,{ }^{* *} \mathrm{P}<0.01$ and ${ }^{* * *} \mathrm{P}<0.001$. Th17, Thelper 17; IL-17, interleukin-17; ROR $\gamma \mathrm{t}$, retinoic acid receptor-related orphan receptor $\gamma \mathrm{t}$.

the development and function of Th17 cells, and thus the levels of ROR $\gamma \mathrm{t}$ in the cardiac allografts were detected by RT-qPCR. The results demonstrated that, compared with the untreated group, the ROR $\gamma t$ levels were decreased in the simvastatin, rapamycin, or simvastatin+rapamycin group (Fig. 5G-I). There results provided further evidence for the effect of combined treatment with simvastatin and rapamycin on Th17 cells in the allografts.

Combined treatment with simvastatin and rapamycin increases regulatory $T$ (Treg) cells in the allografts. The levels of Treg cells in the allografts were detected by flow cytometry. Compared with the untreated group, the levels of Treg cells in the allografts of rapamycin group were increased. Furthermore, a higher level of Treg cells was observed in the simvastatin+rapamycin group (Fig. 6A-F). These results demonstrated that combined treatment with simvastatin and rapamycin increased the levels of Treg cells in the allografts. FOXP3 has a close association with the development and function of Treg cells, and thus the FOXP3 levels were detected by RT-qPCR. The results revealed that the levels of FOXP3 were increased following combined treatment with simvastatin and rapamycin when compared with the untreated group (Fig. 6G-I).

\section{Discussion}

In the present study, the effect of combined treatment with simvastatin and rapamycin on cardiac transplantation rejection was investigated. Combined treatment was observed to 
A
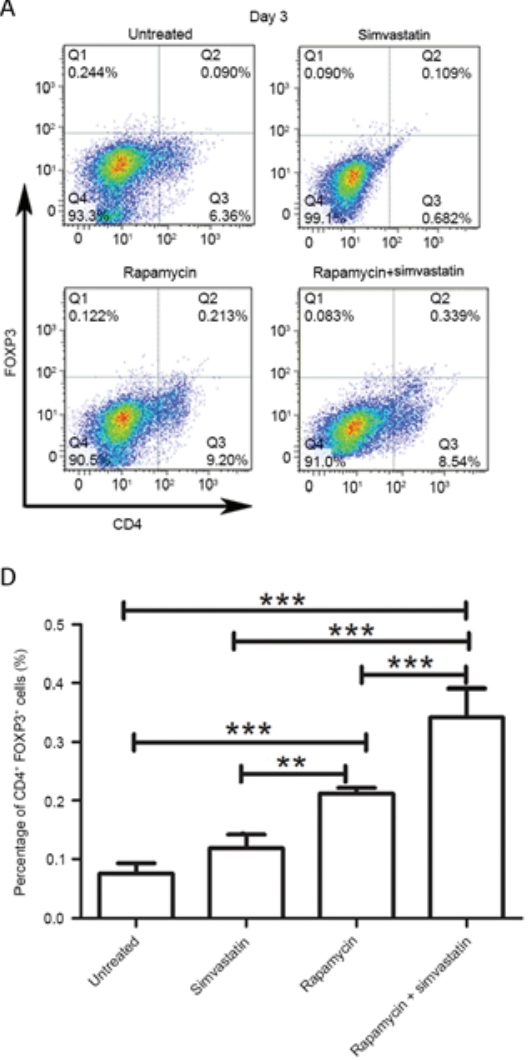

G

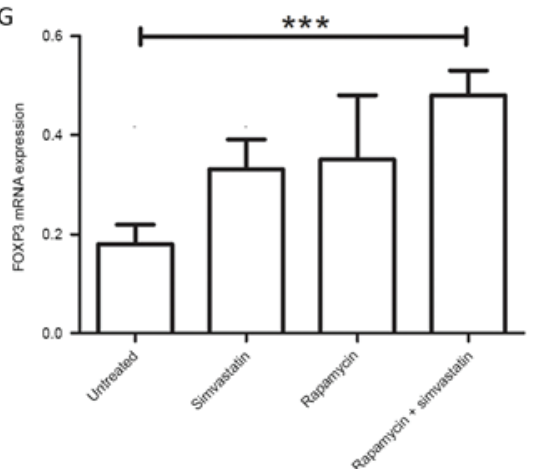

B
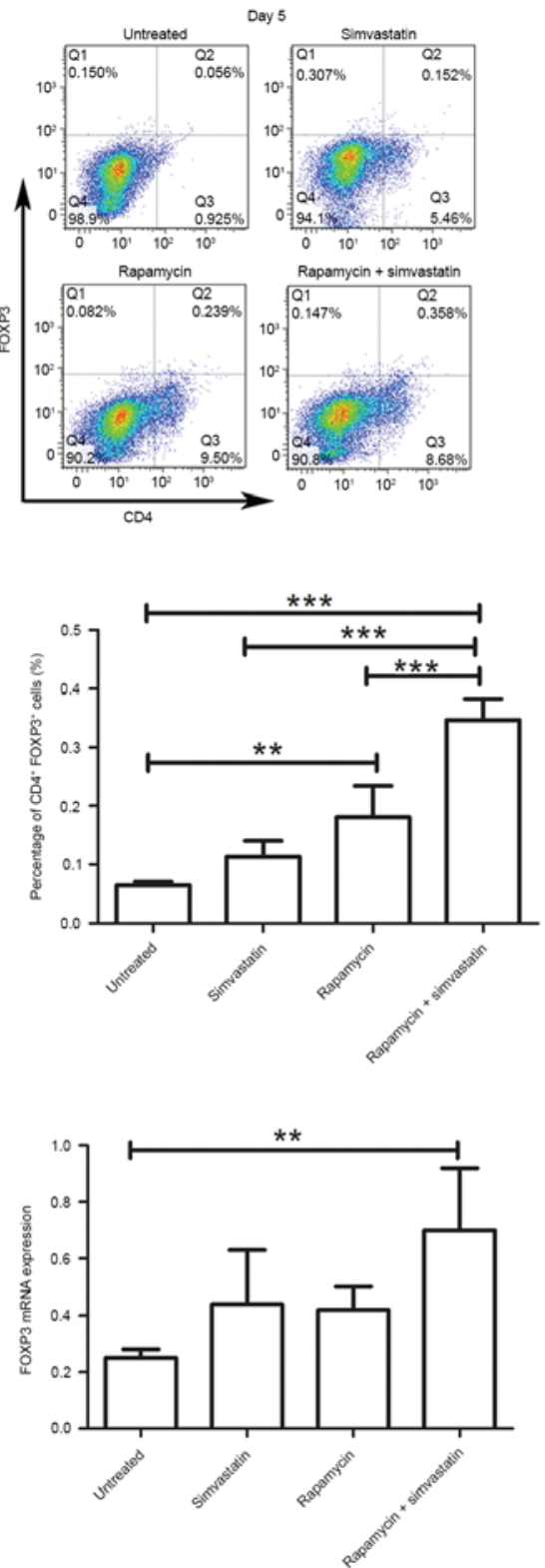

C
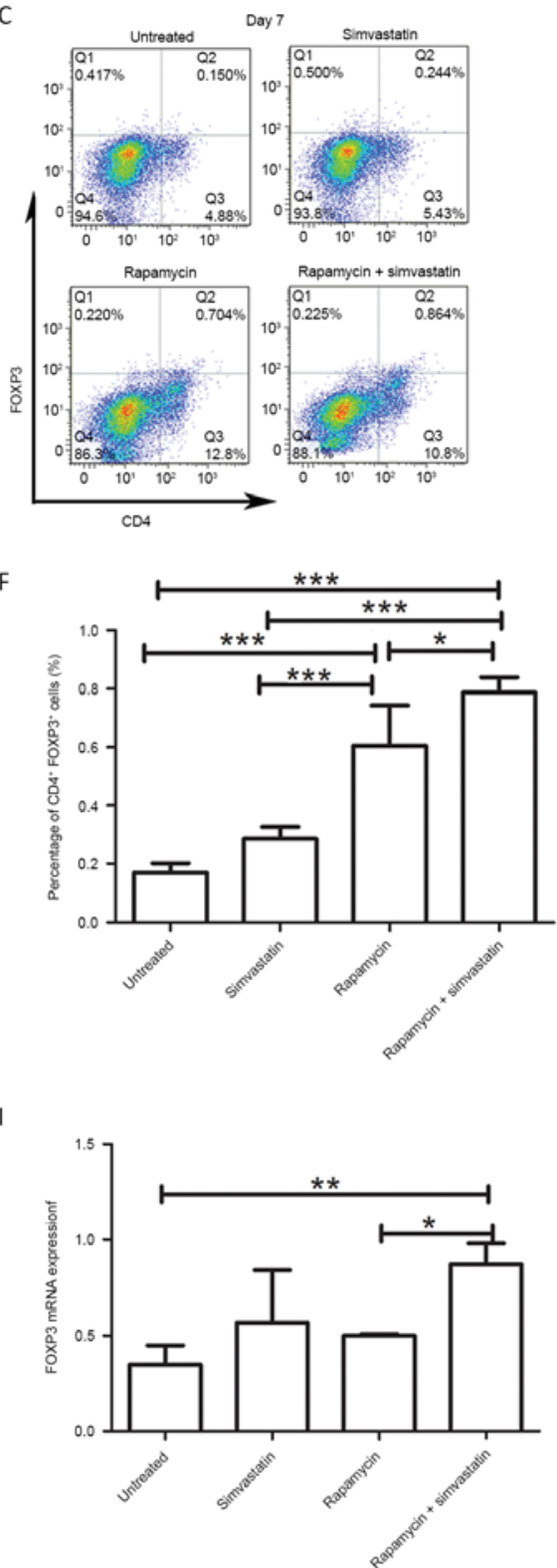

Figure 6. Combined treatment with simvastatin and rapamycin increased the levels of Treg cells in the allografts. Flow cytometry was used to analyze the Treg cells in the allografts on (A) day 3, (B) day 5 and (C) day 7 post cardiac transplantation. The percentages of Treg cells in the allografts are shown on (D) day 3 , (E) day 5 and (F) day 7, as measured by flow cytometry. The mRNA levels of FOXP3 in the allografts were detected by reverse transcription-quantitative polymerase chain reaction on $(\mathrm{G})$ day $3,(\mathrm{H})$ day 5 and (I) day 7 after cardiac transplantation and treatment with simvastatin and rapamycin (n=4). "P<0.05, ${ }^{* *} \mathrm{P}<0.01$ and ${ }^{* * *} \mathrm{P}<0.001$. Treg, regulatory T; FOXP3, forkhead box P3.

prolong the survival time of rats and attenuate the pathological damages. Further investigation demonstrated that Th17 and Treg cells were also affected by the combined treatment. The results of the present study demonstrated that combined treatment with simvastatin and rapamycin may be a promising adjuvant therapy to protect against rejection following cardiac transplantation.

In the current study, combined treatment with simvastatin and rapamycin demonstrated a protective effect against allograft rejection, prolonging the survival time and attenuating pathological damages. Simvastatin has been reported to perform an immunomodulatory function, inhibiting the proliferation and lowering the viability of $\mathrm{T}$ cells $(17,18)$. Donor simvastatin treatment has been demonstrated to prevent against allograft rejection by reducing the inflammatory response, as well as attenuating myocardial fibrosis and ischemia/reperfusion injury (19). Simvastatin is also able to delay the accumulation of intragraft chemokines and the expression of chemokine receptors, thus attenuating cardiac allograft vasculopathy (20). In the present study, treatment with simvastatin alone was found to prolong the survival time of rats following cardiac transplantation; however, the pathological damage was not significantly attenuated.

Rapamycin is an oral immunosuppressant that is able to increase the proliferation of Treg cells and suppress the release of inflammatory factors $(21,22)$. In the present study, treatment with rapamycin alone prolonged the survival of rats and attenuated the pathological damage. Rapamycin has been previously used as an immunosuppressant to treat the rejection response following organ transplantation. However, due to its 
inefficiency at low dosage and side effects, the clinical application of rapamycin is limited (23).

In clinical practice, a combination of immunosuppressants is commonly used by transplant recipients to enhance the efficacy and to lower the occurrence of adverse side effects. In the present study, combined treatment with simvastatin and rapamycin demonstrated an enhanced protective effect on the cardiac transplantation rejection. Additionally, it has been reported that this combined does not cause adverse side effects (24). Treatment with simvastatin reverses the proliferation, migration and cell apoptosis of cardiac microvascular endothelial cells impaired by rapamycin (25). Furthermore, rapamycin exerts a synergistic effect with Treg cells to prevent against allograft rejection (26-28). These observations suggest that combined treatment with simvastatin and rapamycin may be a promising adjuvant therapy to relieve allograft rejection following cardiac transplantation.

The immune system serves an important role in transplantation rejection, and since the spleen is associated with immune responses, it has been reported that the survival of allografts was prolonged following splenectomy (29). In the present study, the levels of $\mathrm{CD}^{+}$and $\mathrm{CD}^{+} \mathrm{T}$ cells in the spleen were decreased subsequent to combined treatment with simvastatin and rapamycin. These results indicate that the protective effect of simvastatin and rapamycin against cardiac rejection may be associated with the immune system.

Th17 and Treg serve important roles in transplantation rejection. Th17 mediates chronic allograft rejection and functions as a barrier to allograft tolerance $(30,31)$. In addition, Treg cells contribute to the induction and maintenance of tolerance to allografts and prolong graft survival $(32,33)$. The imbalance of Th17/Treg cells is associated with transplantation rejection (34), and therapies modulating the balance of Th17/Treg are considered to be promising in the transplantation rejection prevention. The current study observed that simvastatin and rapamycin treatment resulted in decreased levels of Th17 cells, whereas the levels of Treg cells were increased. Therefore, these results suggest that combined treatment with simvastatin and rapamycin may perform a protective effect against cardiac rejection through the regulation of Th17 and Treg cells.

In conclusion, the present study demonstrated that combined treatment with simvastatin and rapamycin prolonged the survival of rats and reduced histopathological damage, thus attenuating cardiac allograft rejection, through the regulation of Th17 and Treg cells. Therefore, combined treatment with simvastatin and rapamycin may be a promising adjuvant therapy for the reduction of rejection following cardiac transplantation.

\section{Acknowledgements}

The present study was supported by grants from the National Natural Science Foundation of China (nos. 81270188 and 81401203) and the Natural Science Foundation for Outstanding Youth of Heilongjiang Province China (no. JC2015020).

\section{References}

1. Miniati DN and Robbins RC: Heart transplantation: A thirty-year perspective. Annu Rev Med 53: 189-205, 2002.
2. Fehr T, Kahlert C, Fierz W, Joller-Jemelka HI, Riesen WF, Rickli H, Wüthrich RP and Ammann P: Statin-induced immunomodulatory effects on human T cells in vivo. Atherosclerosis 175: 83-90, 2004.

3. Vallakati A, Reddy S, Dunlap ME and Taylor DO: Impact of statin use after heart transplantation: A meta-analysis. Circ Heart Fail 9: e003265, 2016.

4. Luo CM, Chou NK, Chi NH, Chen YS, Yu HY, Chang CH, Wang $\mathrm{CH}$, Tsao CI and Wang SS: The effect of statins on cardiac allograft survival. Transplant Proc 46: 920-924, 2014.

5. Kittleson MM and Kobashigawa JA: Statins in heart transplantation. Clin Transpl: 135-143, 2013.

6. Protty MB, Lacey A, Hayes J and Freeman P: Statins for secondary prevention: Clinical use in patients with acute coronary syndrome in Wales. Future Cardiol 13: 137-141, 2017.

7. Pang X, Si J, Xu S, Li Y and Liu J: Simvastatin inhibits homocysteine-induced CRP generation via interfering with the ROS-p38/ERK1/2 signal pathway in rat vascular smooth muscle cells. Vascul Pharmacol 88: 42-47, 2017.

8. Tuuminen R, Holmström E, Raissadati A, Saharinen P, Rouvinen E, Krebs R and Lemström KB: Simvastatin pretreatment reduces caspase-9 and RIPK1 protein activity in rat cardiac allograft ischemia-reperfusion. Transpl Immunol 37: 40-45, 2016.

9. Chaoul N, Fayolle C, Desrues B, Oberkampf M, Tang A, Ladant D and Leclerc C: Rapamycin impairs antitumor CD8+ T-cell responses and vaccine-induced tumor eradication. Cancer Res 75: 3279-3291, 2015.

10. Merino D, San Segundo D, Medina JM, Rodrigo E, Asensio E, Irure J, Fernández-Fresnedo G, Arias MA and López-Hoyos M: Different in vitro proliferation and cytokine-production inhibition of memory T-cell subsets after calcineurin and mammalian target of rapamycin inhibitors treatment. Immunology 148: 206-215, 2016.

11. Salehi M, Bagherpour B, Shayghannejad V, Mohebi F and Jafari R: Th1, Th2 and Th17 Cytokine profile in patients with multiple sclerosis following treatment with Rapamycin. Iran J Immunol 13: 141-147, 2016.

12. Kelly MA, Kaplan M, Nydam T, Wachs M, Bak T, Kam I and Zimmerman MA: Sirolimus reduces the risk of significant hepatic fibrosis after liver transplantation for hepatitis $\mathrm{C}$ virus: A single-center experience. Transplant Proc 45: 3325-3328, 2013.

13. Mancini D, Pinney S, Burkhoff D, LaManca J, Itescu S, Burke E, Edwards N, Oz M and Marks AR: Use of rapamycin slows progression of cardiac transplantation vasculopathy. Circulation 108: 48-53, 2003.

14. National Research Council: Guide for the Care and Use of Laboratory Animals. The National Academies Press (US), Washington, DC, 1996.

15. Wu J, Zhou C, Chen W, Xie A, Li J, Wang S, Ye P, Wang W and Xia J: Digoxin attenuates acute cardiac allograft rejection by antagonizing ROR $\gamma t$ activity. Transplantation 95: 434-441, 2013.

16. Livak KJ and Schmittgen TD: Analysis of relative gene expression data using real-time quantitative PCR and the 2(-Delta Delta C(T)) method. Methods 25: 402-408, 2001.

17. Ghittoni R, Patrussi L, Pirozzi K, Pellegrini M, Lazzerini PE, Capecchi PL, Pasini FL and Baldari CT: Simvastatin inhibits T-cell activation by selectively impairing the function of Ras superfamily GTPases. FASEB J 19: 605-607, 2005.

18. Jameel A, Ooi KG, Jeffs NR, Galatowicz G, Lightman SL and Calder VL: Statin modulation of human T-Cell proliferation, IL-1 $\beta$ and IL-17 production, and IFN- $\gamma$ T Cell expression: Synergy with conventional immunosuppressive agents. Int $\mathrm{J}$ Inflam 2013: 434586, 2013.

19. Tuuminen R, Syrjälä S, Krebs R, Keränen MA, Koli K, Abo-Ramadan U, Neuvonen PJ, Tikkanen JM, Nykänen AI and Lemström KB: Donor simvastatin treatment abolishes rat cardiac allograft ischemia/reperfusion injury and chronic rejection through microvascular protection. Circulation 124: 1138-1150, 2011.

20. Yin R, Zhu J, Shao H, Cheng X, Feng X, Li Z and Jing H: Inhibition of chemokine receptor CCR 2 and CCR 5 expression contributes to simvastatin-induced attenuation of cardiac allograft vasculopathy. J Heart Lung Transplant 26: 485-493, 2007.

21. Donia M, Mangano K, Amoroso A, Mazzarino MC, Imbesi R, Castrogiovanni P, Coco M, Meroni P and Nicoletti F: Treatment with rapamycin ameliorates clinical and histological signs of protracted relapsing experimental allergic encephalomyelitis in Dark Agouti rats and induces expansion of peripheral CD4+CD25+Foxp3+regulatory T cells. J Autoimmun 33: 135-140, 2009. 
22. Esposito M, Ruffini F, Bellone M, Gagliani N, Battaglia M, Martino $G$ and Furlan R: Rapamycin inhibits relapsing experimental autoimmune encephalomyelitis by both effector and regulatory T cells modulation. J Neuroimmunol 220: 52-63, 2010.

23. Saunders RN, Metcalfe MS and Nicholson ML: Rapamycin in transplantation: A review of the evidence. Kidney Int 59: 3-16, 2001.

24. Taveira-DaSilva AM, Jones AM, Julien-Williams PA, Stylianou M and Moss J: Retrospective review of combined sirolimus and simvastatin therapy in lymphangioleiomyomatosis. Chest 147: 180-187, 2015.

25. Pan Q, Xie X, Guo Y and Wang H: Simvastatin promotes cardiac microvascular endothelial cells proliferation, migration and survival by phosphorylation of p70 S6K and FoxO3a. Cell Biol Int 38: 599-609, 2014

26. Raimondi G, Sumpter TL, Matta BM, Pillai M, Corbitt N, Vodovotz Y, Wang Z and Thomson AW: Mammalian target of rapamycin inhibition and alloantigen-specific regulatory $\mathrm{T}$ cells synergize to promote long-term graft survival in immunocompetent recipients. J Immunol 184: 624-636, 2010.

27. Zhang C, Shan J, Lu J, Huang Y, Feng L, Long D, Li S, Li Q and $\mathrm{Li}$ Y: Rapamycin in combination with donor-specific CD4+CD25+Treg cells amplified in vitro might be realize the immune tolerance in clinical organ transplantation. Cell Immunol 264: 111-113, 2010

28. Ma A, Qi S, Wang Z, Massicotte E, Dupuis M, Daloze P and Chen H: Combined therapy of CD4(+)CD25(+) regulatory T cells with low-dose sirolimus, but not calcineurin inhibitors, preserves suppressive function of regulatory $\mathrm{T}$ cells and prolongs allograft survival in mice. Int Immunopharmacol 9: 553-563, 2009.
29. Zhu XH, Chen S and Chen ZK: Prolonged heart allograft survival resulted from donor-specific T-cell sequestering and removal by selective splenectomy in mice. Transplant Proc 36: 2448-2449, 2004.

30. Abadja F, Sarraj B and Ansari MJ: Significance of T helper 17 immunity in transplantation. Curr Opin Organ Transplant 17: 8-14, 2012.

31. Chadha R, Heidt S, Jones ND and Wood KJ: Th17: Contributors to allograft rejection and a barrier to the induction of transplantation tolerance? Transplantation 91: 939-945, 2011.

32. Wood KJ: Regulatory $\mathrm{T}$ cells in transplantation. Transplant Proc 43: 2135-2136, 2011.

33. Lee MK IV, Moore DJ, Jarrett BP, Lian MM, Deng S, Huang X, Markmann JW, Chiaccio M, Barker CF, Caton AJ and Markmann JF: Promotion of allograft survival by CD4+CD25+ regulatory T cells: Evidence for in vivo inhibition of effector cell proliferation. J Immunol 172: 6539-6544, 2004.

34. Hanidziar D and Koulmanda M: Inflammation and the balance of Treg and Th17 cells in transplant rejection and tolerance. Curr Opin Organ Transplant 15: 411-415, 2010. 